\section{Conventional Impression vs Optical Impression: The Battle has already Begun}

\section{Abstract}

The most important step in prosthetic restoration is the impression, for centuries, the conventional impression has always been used in dentistry therefore the introduction of digital impression has revolutionized our prosthetic approach.

Keywords: Optical impression; Conventional impression; Camera; Prosthodontics

Received: September 19, 2016; Accepted: October 08, 2016; Published: October 11, 2016

\section{Introduction}

Digital impression was introduced in dentistry in the middle 1980, the father of optical impression Pr. Fronçois Duret, states the Digital Impression will overcome many imprecision in the prosthetic chain due to the materials and or human errors [1].

Since our main subject is the optical impression consequently we need cameras. As you can see there are many types! Such as: iTero; Omnicam by CEREC; NEVO; $3 \mathrm{M}$ true definition; TRIOS from 3 shape and finally IOS fast scan (Figure 1) [2].

The procedure consists of isolation of the prepared teeth, coating with di oxyde titane if we use système CEREC (Bluecam) or powder free scanning with color image data for the case if we use itero, that's Allow immediate evaluation of preparation and margins (Figure 2) [3].

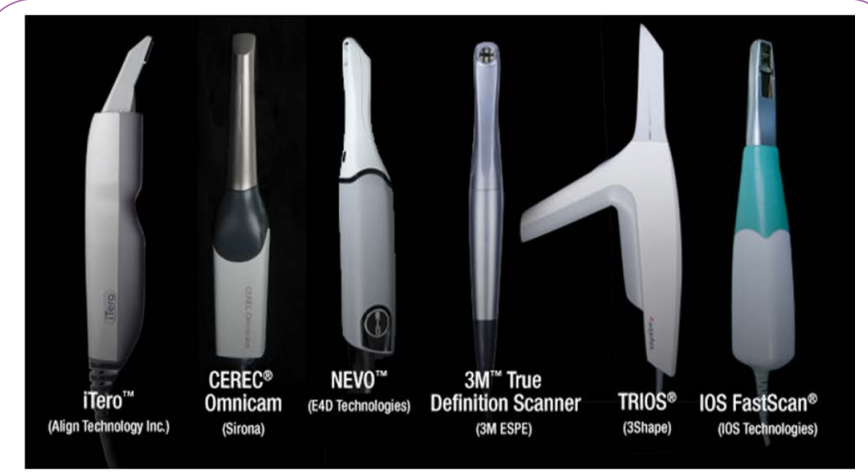

Figure 1 Different types of camera.

\section{Zenati Latifa and Boukais Hamid}

Department of Dentistry, University Saad Dahlab of Blida, Algéria

\section{Corresponding author: Zenati Latifa \\ ”zenlatifa@yahoo.fr}

PhD in Prosthodontics, Department of Dentistry, University Saad Dahlab of Blida, Algéria.

Tel: +213556812584

Citation: Latifa Z, Hamid B. Conventional Impression vs Optical Impression: The Battle has already Begun. Periodon Prosthodon. 2016, 2:3.

At least we need to have three impressions: prepared arch, antagonist arch, and the occlusion a virtual 3D model from those images. Contribute to a minimum need for occlusal adjustment in final restoration (Figure 3) [4,5].

\section{How is Optical Impression More Efficient than Conventional Impression?}

Well It was found that the digital impression procedure takes significantly less time (6 $\mathrm{min} 39 \mathrm{~S})$ than the conventional impression which takes (12 min $13 \mathrm{~S}$ ), it's more faster=less chair time which mean the increasement of $50 \%$ productivity $[6,7]$.

We gain time by eliminating steps in the office such as: tray selection, there is no more Bubbles in the impression material or problems with separated impression material from the tray, disinfection, Moreover We obtain a virtual model, therefore it will delete all steps: Pour plaster, cut cast and dies, trimming, application of Die spacer, articulation besides each chemical step in the process accumulate errors in the treatment and also in the manufacturing cycle and shipping $[8,9]$.

In the other hand, if we compare the two techniques! The optical impression requires less materials, steps and time comparing to 

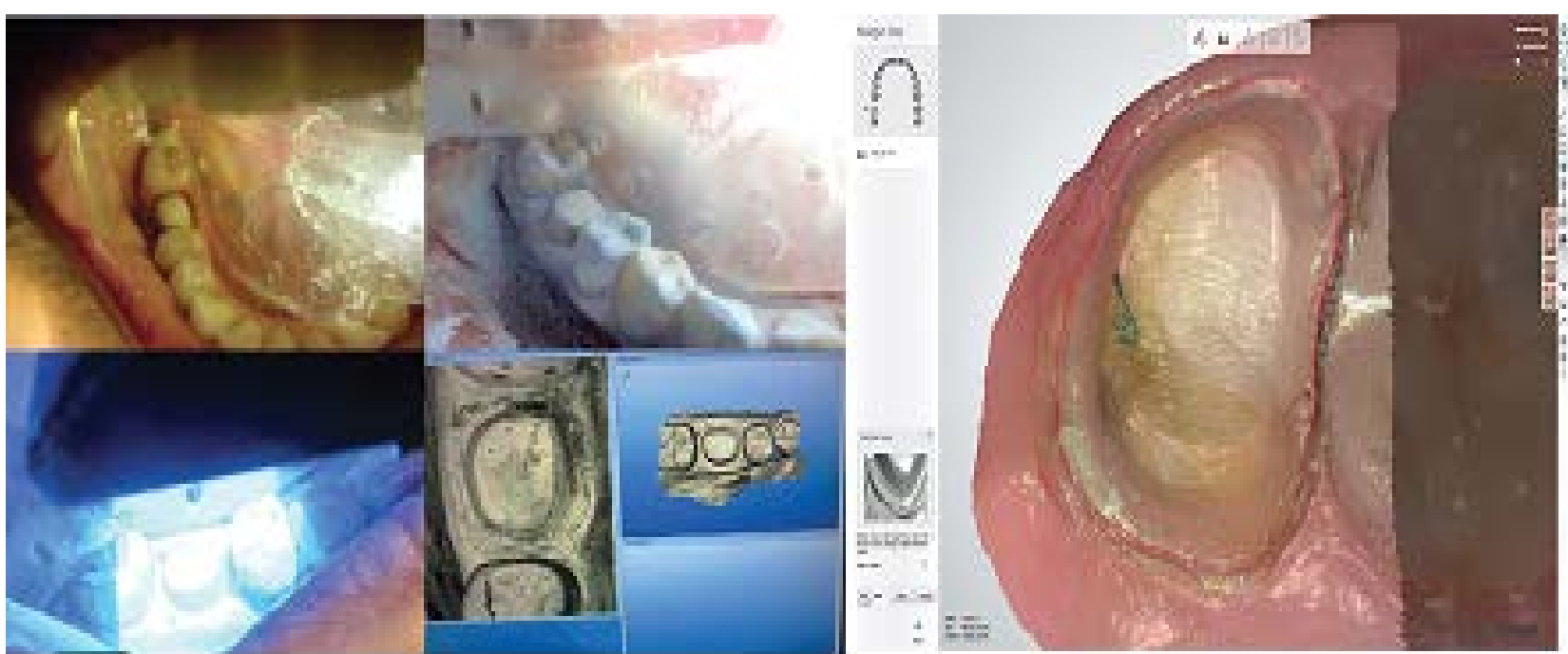

Figure 2 Optical impression with CEREC system «coating with di oxyde de titane » in the left image. In the right 3D color image by 3 shape with powder free.

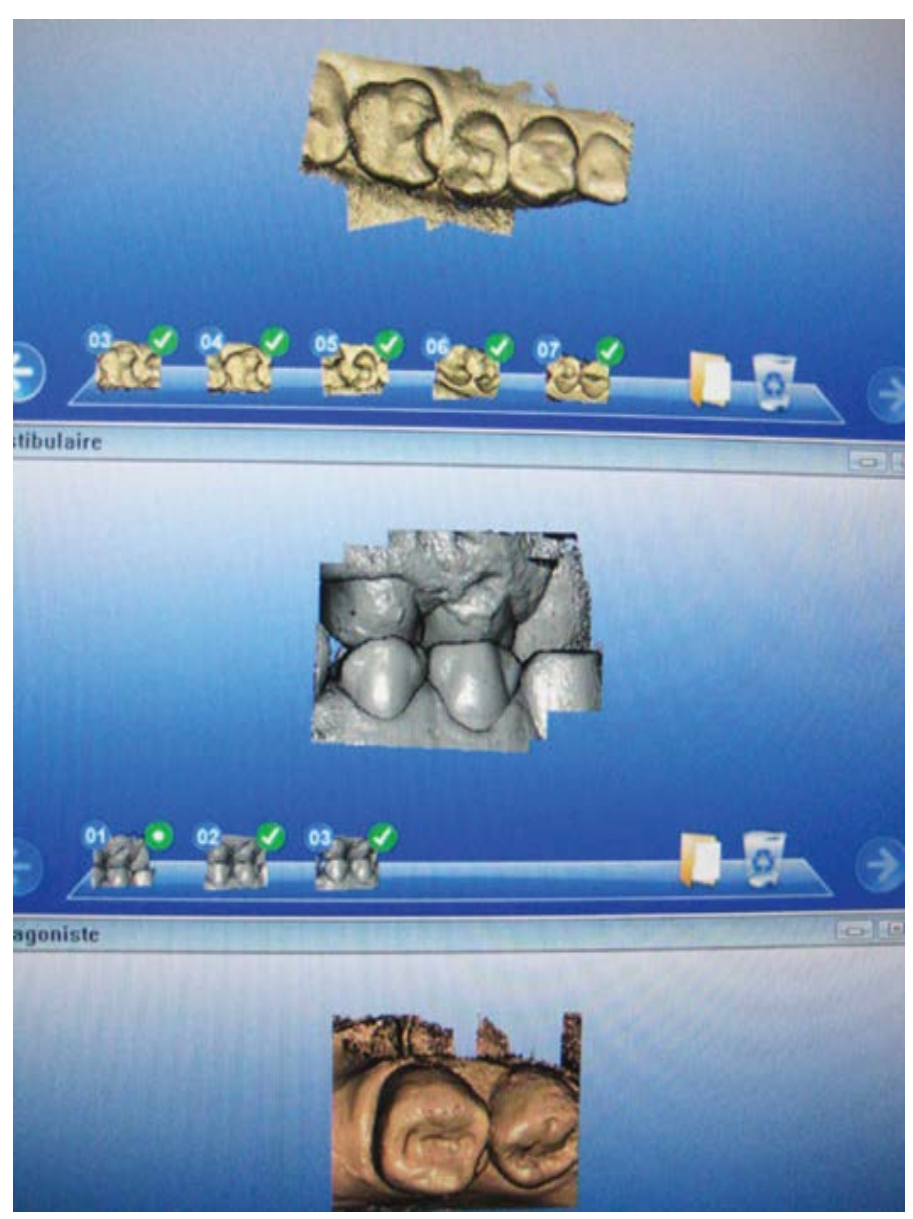

Figure 3 Three impressions; one of the prepared arch, second for the antagonist and the third in bite.

the physical impression.

- Imprecisions simultaneously more efficiency and accuracy

- As a result less time with more productivity in clinics and labs
- The digital impression can be stored electronically indefinitely, which saves space

- Tomorrow's dental laboratory is virtual

- For our patients comfort, No gag reflex any more with 
less chair time and they have tendencies for the digital impression technic rather than physical impression.

- That's will Gives a competitive advantage

\section{Discussion}

Of course, the optical impression has its limits such as high cost and the requirement of specific equipment about 4000 dollar. The in vitro studies show within their limitation that PVS is the most accurate impression material.

\section{Conclusion}

Digital and traditional impressions offer unique benefits and challenges. For patients with extensive bleeding, conventional impressions are best, because a digital scanner cannot detect what it cannot see. These methods are totally different but leads to the same result in the end, therefore we expect that optical impression will replace gradually the conventional in the next future. 


\section{References}

1 Chabreron O (2014) Planification implantaire par CFAO à partir d'un projet prothétique et chirurgie assistée par ordinateur: état des lieux, avancées et perspectives. University of Toulouse, France.

2 D'haese J, Van De velde T, Komiyama A, Hultin M, De Bruyun $H$ (2012) Accuracy and complications using computer-designed stereolithographic surgical guides for oral rehabilitation by means of dental implants: a review of the literature. Clin Implant Dent Relat Res 14: 321-335.

3 Ender A, Mehl A (2011) Full arch scans: conventional versus digital impressions - an in-vitro study 14: 11-21.

4 Cyril G (2011) Implantologie et CFAO: Le Fil dentaire dentaire $N^{\circ} 59$ Janvier. Techno Implantologie, France, pp: 44-46.
5 Franck A, Christophe HUE (2010) implantologie assistée par ordinateur: traitement d'un édentement complet maxillaire à l'aide du systéme Nobel Guide system. Le Fil Dentaire, France.

6 Gian LT (2012) Nouveaux concepts d'implontologie guidée par ordinateur. Part I: Forage en temps réel et phase d'implant. Studio Odontoiatrico Lippi Telara, Italy.

7 Stéphanie G (2012) La chirurgie implantaire guidée assistée par ordinateur. Universite De Lorraine, France.

8 Bart D (2009) Blue light for perfect optical impressions. Cerec Zeitung International edition, Sirona Dental Systems GmbH, Germany.

9 Claire C, Alain H (2015) N022 : Apport de l'empreinte optique pour la réalisation des restaurations supra-implantaire. Training and Research Unit of Dentistry, University of Nantes, France. 